\title{
Reaction mechanisms and catalysis in the one-step synthesis of methylal via methanol oxidation
}

\author{
Meng Yuan ${ }^{1}$, Mengru Dong ${ }^{1}$, Zhiwei Tian $^{1}$, Yuanjun $\mathrm{Che}^{1}$, Yuanyu Tian ${ }^{1}$, Yingyun Qiao ${ }^{2}$, \\ Jingong Zhang ${ }^{2}$, and Dawei $\mathrm{Li}^{1}$ \\ ${ }^{1}$ Affiliation not available \\ ${ }^{2}$ China University of Petroleum East China - Qingdao Campus
}

November 13, 2021

\begin{abstract}
This paper reports on the scaling-up of a one-step methanol production process from the laboratory scale to the pilot scale. This lays the foundation for the industrialization of a one-step process for preparing DMM from methanol. After a long period of operation in the circulating fluidized bed, the Fe-Mo/HZSM-5 catalyst was shown to have high stability and carbon deposition resistance, and the regeneration effect of the circulating regeneration fluidized bed was better. In addition, in-situ DRIFTS was used to explore the effects of reaction time, the Mo-Fe ratio and carrier Si-Al ratio on the reaction and product distribution. It was found that the synergistic effect of oxidation centers and acid centers was the fundamental reason for the excellent catalytic performance of the Fe-Mo/HZSM-5 catalyst. And proposed the reaction mechanisms in the one-step synthesis of methylal via methanol oxidation.
\end{abstract}

Reaction mechanisms and catalysis in the one-step synthesis of methylal via methanol oxidation Meng Yuan ${ }^{\mathrm{a}, \mathrm{c}}$, Mengru Dong ${ }^{\mathrm{a}}$, Zhiwei Tian ${ }^{\mathrm{e}}$, Yuanjun Che ${ }^{\mathrm{b}}$, Yuanyu Tian ${ }^{\mathrm{a}, \mathrm{c}, \mathrm{d}^{*},}$ Yingyun Qiao ${ }^{\mathrm{a}, \mathrm{c}^{*}}$, Jinhong Zhang ${ }^{\mathrm{a}, \mathrm{c}}$, Dawei Li ${ }^{\text {a,c }}$

${ }^{a}$ State Key Laboratory of Heavy Oil Processing, China University of Petroleum (East China), Qingdao Shandong 266580, China.

b School of Environmental and Chemical Engineering, Xi'an Polytechnic University, Xi'an, Shaanxi, 710048, China

${ }^{\mathrm{c}}$ Shandong Engineering and Technology Research Center of High Carbon Low Carbonization, China University of Petroleum (East China), Qingdao 266580, PR China

d Key Laboratory of Low Carbon Energy and Chemical Engineering, Shandong University of Science and Technology, Qingdao Shandong 266590, China.

e Jiangsu Co-Innovation Center of Efficient Processing and Utilization of Forest Resources, International Innovation Center for Forest Chemicals and Materials, College of Materials Science and Engineering, Nanjing Forestry University, Nanjing, 210037, China.

${ }^{*}$ Corresponding author. Tel.: +86-0532-86057766. E-mail addresses: tianyy1008@126.com (Y. Tian); qiao_yingyun@126.com (Y. Qiao)

Abstract : 
This paper reports on the scaling-up of a one-step methanol production process from the laboratory scale to the pilot scale. This lays the foundation for the industrialization of a one-step process for preparing DMM from methanol. After a long period of operation in the circulating fluidized bed, the Fe-Mo/HZSM-5 catalyst was shown to have high stability and carbon deposition resistance, and the regeneration effect of the circulating regeneration fluidized bed was better. In addition, in-situ DRIFTS was used to explore the effects of reaction time, the $\mathrm{Mo}-\mathrm{Fe}$ ratio and carrier $\mathrm{Si}-\mathrm{Al}$ ratio on the reaction and product distribution. It was found that the synergistic effect of oxidation centers and acid centers was the fundamental reason for the excellent catalytic performance of the Fe-Mo/HZSM-5 catalyst. And proposed the reaction mechanisms in the one-step synthesis of methylal via methanol oxidation.

Key words: DMM, Pilot-scale process, In-situ DRIFTS, Reaction mechanisms

\section{Introduction}

Methanol is mainly produced from synthesis gas, which is usually obtained from methane or coal. ${ }^{1}$ Although currently there is surplus global methanol production capacity ${ }^{2}$, with the continuous development of methanol applications, methanol - which is the cornerstone product of $\mathrm{C} 1$ chemistry - has promising market prospects $^{3}$. Recently, the production of "bioethanol" has commenced at a new plant for processing biomass synthesis gas ${ }^{4}$. Methanol can now be considered as a sustainable platform compound with very promising chemical applications.

\section{Redox site catalyzed}

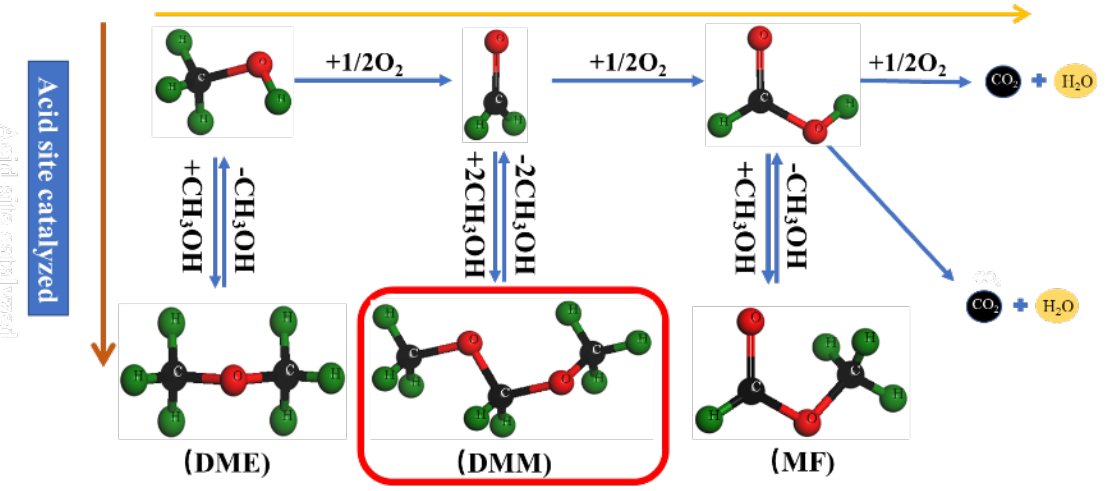

Scheme 1 Methanol oxidation pathways (adapted from ref. 16).

Dimethoxymethane (DMM) is a chemically stable compound with many uses, including as a solvent, pharmaceutical and fuel-additive applications ${ }^{5}$. For example, the selective oxidation of DMM can be used to prepare concentrated formaldehyde (FA) solution ${ }^{6}$. Due to its low toxicity, It is also an excellent solvent with low toxicity that is used in the pharmaceutical and perfume industries ${ }^{7}$. The polyoxymethylene dimethyl ether $(\mathrm{PODE})^{8}$ synthesized from DMM can be mixed with diesel to reduce its freezing point while increasing the combustion efficiency, decreasing COx and NOx emissions in diesel exhaust, or it can be used in fuel cells in a low-toxic and efficient way ${ }^{9}$. PODE is also used as a preservative, which is safer and healthier than FA ${ }^{10}$.

Industrially, DMM is produced by reaction catalyzed polycondensation of FA produced by the oxidation of methanol and methanol ${ }^{11}$. However, this traditional method is complicated and expensive due to the high reaction temperature of the acid catalyst and the resulting corrosion of the equipment ${ }^{12}$. Considering that the one-step selective oxidation of methanol to DMM is economical and environmentally friendly, this promising reaction warrants further study ${ }^{13}$. This one-step reaction is very sensitive to the nature of the catalytic active center ${ }^{14}$. Continuous redox reaction and acid catalysis pathways (Scheme 1) ${ }^{15}$ can generate different products. The difficulty of selectively generate DMM explains the dearth of literature reports on this subject ${ }^{16,17}$. However, most of the existing research on dual-functional catalysts for the one-step 
preparation of DMM from methanol has shown that it is possible to increase DMM selectivity ${ }^{18}$, but not to simultaneously increase the methanol conversion; therefore, high DMM yields have not been achieved. The highest previously reported yield of DMM was only $61.38 \%$ (TableS1). However, prior to the present study, our team used Fe-Mo-based dual-function catalysts under optimized conditions in a fluidized bed reactor to achieve the highest DMM yield to date ${ }^{19}$.

This paper reports the scale-up pilot process in the laboratory. This lays the foundation for the in-depth development, popularization and application of this new technology, and potentially the future industrialization of this one-step process to generate DMM from methanol. Using the optimal Fe-Mo/HZSM-5 dual-function catalyst developed by the team, the reaction effect was verified in the circulating regenerated fluidized bed, the optimal process conditions were explored, and the reaction mechanism was probed using In-situ infrared (DRIFTS).

\section{Experimental}

\subsection{Synthesis and characterization of catalysts}

The preparation and characterization of the catalysts are described in detail in the ESI. These methods are consistent with those of previous studies ${ }^{19}$.

\subsection{Operation steps of the equipment}

The fluidized bed device comprised four parts: a feeding system, reaction system, catalyst regeneration system, and separation system. The total height of the laboratory circulating fluidized bed scaled-up reactor is $4300 \mathrm{~mm}$, the reactor, regenerator and separator are $800 \mathrm{~mm}$ long, with an inner diameter of $108 \mathrm{~mm}$, and the riser part is $2100 \mathrm{~mm}$ long and $32 \mathrm{~mm}$ in diameter. It was mainly designed to separate catalyst and gas products in the separation tank. The catalyst enters the regenerator by gravity and the gas products are discharged through a filter in the separation tank and are collected by secondary condensation. There is a filter on the top of the separation tank to further prevent catalyst from being entrained by the product and entering the separation system. The reaction volume of the pilot plant was 11 times larger than that of the laboratory micro-reactor(total length $800 \mathrm{~mm}$, inner diameter $25 \mathrm{~mm})^{19}$, providing a more favourable basis for industrial scale-up. The liquid reaction products are quantitatively analysed by Agilent 7890 A (SE-54 capillary column) gas chromatography, and the gas phase products are quantitatively analysed by molecular sieve packed column TCD thermal conductivity cell. The circulating fluidized bed scaled-up reactor is shown in Fig. 1. The total carbon balance exceeded $97 \pm 2 \%$, which is satisfactory. 


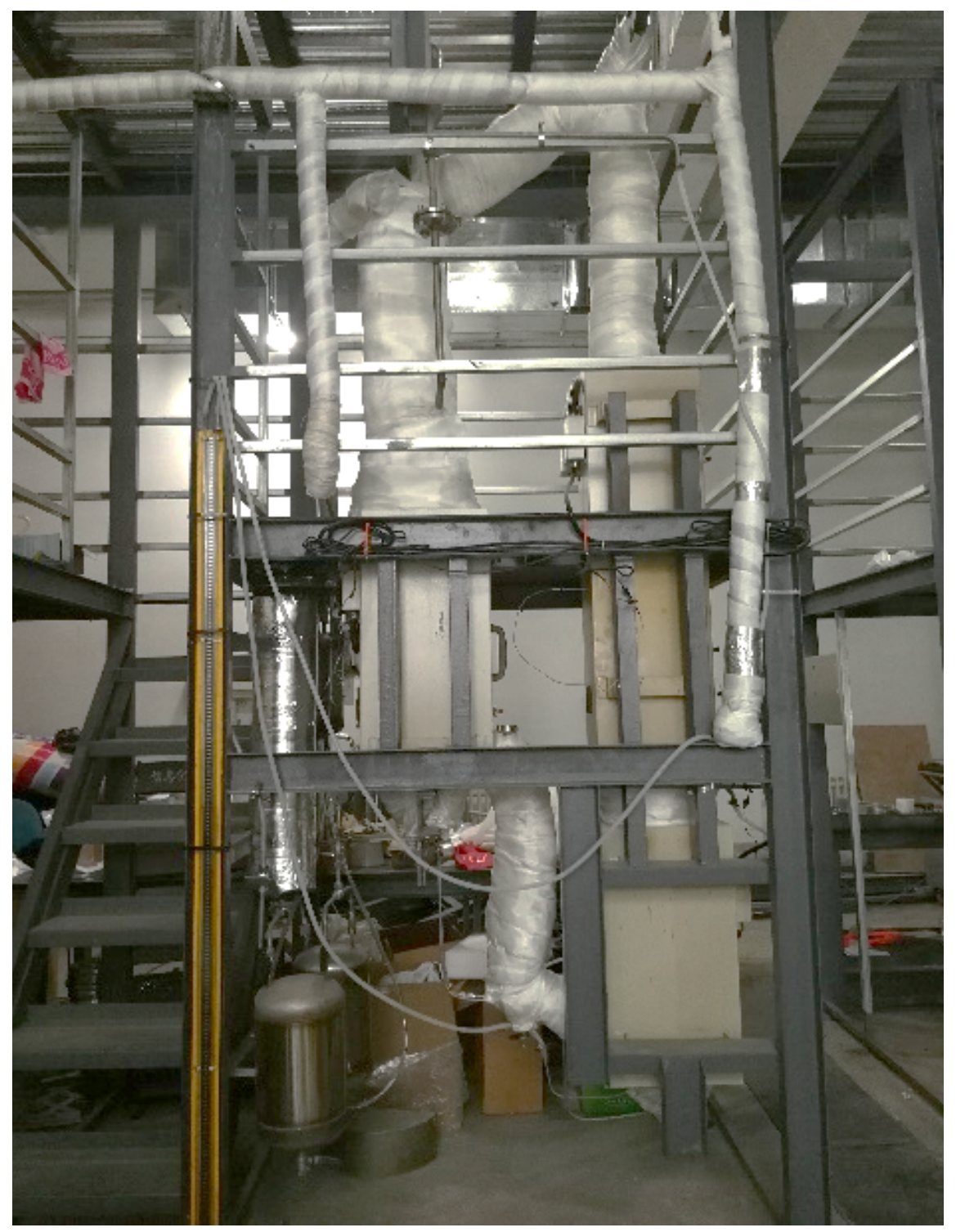

Fig. 1 . Schematic diagram of a circulating fluidized bed scaled-up reactor.

\section{Results anddiscussion}

\subsection{Laboratory scale-up experiment}

We used the Fe-Mo/ZSM-5 dual-function catalyst in the circulating fluidized bed scaled-up reactor to verify the reaction effect after 3 filling cycles and continuous feeding under the same reaction conditions(reaction temperature $=390{ }^{\circ} \mathrm{C}$, methanol/air ratio $=0.5$, reaction space velocity $=15000 \mathrm{~h}^{-1}$ ). The performance of the Fe-Mo/ZSM-5 catalyst in the micro-reactor and the circulating fluidized bed scaled-up reactor were compared in Table1. It can be seen from Table 1 that the methanol conversion rate of the three scaled-up reactors is better than that of the micro fluidized bed reactor. We believe this was because the regenerated catalyst brings more catalytic active centers and accelerates the methanol reaction rate. At the same time, the selectivity decreased for DMM and increased for FA. This was because the regenerated catalyst brings too many oxidation active centers to promote the adsorption of more methanol to form methoxy groups, but it is not desorbed in time for the next polycondensation reaction. Compared with the micro-fluidized 
bed reactor, the pilot-scale test results showed a better conversion rate, indicating that the pilot scale-up experiment of the process was successful. The yield of DMM was as high as $79.6 \%$, which is the best reported in the literature so far(as shown in Table S1). These results indicate that the successful completion of the laboratory micro-reaction to the pilot scale-up process experiment has laid a foundation for the in-depth development, popularization and application of new process technologies.

Table. 1. Catalytic activity of Fe-Mo/ZSM-5 catalyst in micro fluidized bed and Circulating fluidized bed scaled-up reactor.

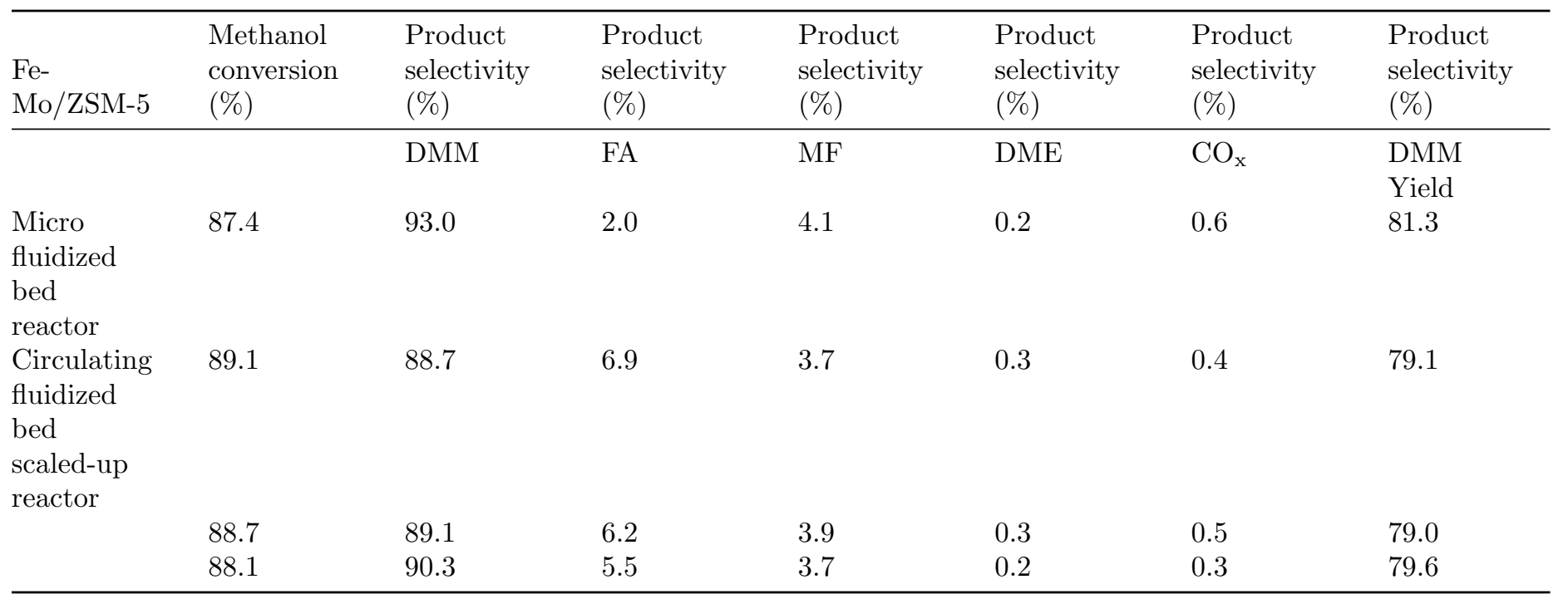

Subsequently, the pilot reactor was used to investigate the effects of the reaction conditions on catalysis. As shown in Table 2, with the change of reaction temperature, the methanol conversion rate fluctuated slightly and the selectivity for DMM and byproducts FA and methyl formate (MF) changed considerably. At $360{ }^{\circ} \mathrm{C}$ and $380^{\circ} \mathrm{C}$, far from equilibrium, the oxidative dehydrogenation of FA from methanol was thermodynamically favorable ${ }^{20}$. The higher temperature was conducive to the activation of the $\mathrm{C}-\mathrm{H}$ bond of $\mathrm{FA}$ by methanol, and the reaction of methanol with FA converted DMM and DME intermediates into FA, methanol and MF ${ }^{11}$. The increase in temperature led to lower DMM selectivity and higher FA and MF selectivity.

Table 2 . Catalytic activity of Fe-Mo/HZSM-5 catalyst in circulating fluidized bed pilot reactor with different temperatures and methanol/air ratios.

\begin{tabular}{lllll}
\hline Fe-Mo/HZSM-5 & Methanol conversion (\%) & Product selectivity (\%) & Product selectivity (\%) & Product selectivity (\%) \\
\hline Temperature $/{ }^{\circ} \mathrm{C}$ & & DMM & FA & MF \\
340 & 84.2 & & & \\
360 & 86.5 & 84.7 & 9.2 & 5.0 \\
380 & 89.1 & 86.2 & 7.9 & 4.8 \\
400 & 88.6 & 88.7 & 6.9 & 3.7 \\
420 & 86.0 & 80.1 & 11.0 & 7.7 \\
$\mathrm{CH}_{3} \mathrm{OH}$ /Air ratio & & 77.5 & 12.8 & 8.4 \\
0.6 & 69.3 & & & \\
0.8 & 71.2 & 84.1 & 19.1 & 5.9 \\
1 & 80.2 & 84.8 & 13.1 & 5.3 \\
1.2 & 89.1 & 88.8 & 9.2 & 5.9 \\
& & & 6.9 & 3.7
\end{tabular}




\begin{tabular}{lllll}
\hline Fe-Mo/HZSM-5 & Methanol conversion (\%) & Product selectivity $(\%)$ & Product selectivity (\%) & Product selectivity (\%) \\
\hline 1.5 & 79.6 & 82.1 & 6.3 & 10.8 \\
\hline
\end{tabular}

Simultaneously, as the methanol/air ratio increased, the reaction rate first increased and then decreased. The side reaction that occurs in the synthesis of DMM (continuous bimolecular coupling of methanol and its derivative intermediates with $\mathrm{FA}$ ) forms by-products and $\mathrm{DMM}^{21}$. As the methanol/air ratio increased, the enhancement of these secondary reactions led to an increase in the FA conversion rate and decreases in the DMM formation rate and selectivity ${ }^{22}$. At the same time, it was observed that the MF selectivity increased from $5.9 \%$ to $10.8 \%$, which is consistent with the expected properties of the methanol bimolecular dehydration reaction.

Fig. 2 . Example of long-term reaction test using the Fe-Mo/ZSM-5 catalyst.

The long-term experimental results regarding the Fe-Mo/ZSM-5 catalyst in the circulating regenerating fluidized bed are shown in Fig. 2 (Table S2). The methanol conversion rate and DMM selectivity remained basically unchanged in the first 30 minutes. After 60 minutes, the catalyst activity decreased significantly, the methanol selectivity decreased to $87.6 \%$, and the DMM selectivity decreased to $87.0 \%$. It can be seen from Figure 2 that the catalytic activity was stable and high catalytic activity was still maintained with the extension of the fluidization bed reaction time, with a DMM yield of about $76 \%$. The Fe-Mo/ZSM5 catalyst showed better stability in the circulating regenerating fluidized bed, which was consistent with actual industrial FA production. The scanning electron microscopy (SEM) image (Fig. S1) of the catalyst after the long-term stability test showed that its apparent morphology did not change, with fresh HZSM-5 also having a hexagonal prism morphology ${ }^{23}$, nor was it found on the surface. The presence of four phases, $\mathrm{Fe}_{2}\left(\mathrm{MoO}_{4}\right)_{3}, \mathrm{Fe}_{2} \mathrm{O}_{3}, \mathrm{MoO}_{3}$, and $\beta-\mathrm{Fe}_{2}\left(\mathrm{MoO}_{4}\right)_{3}$, was confirmed by X-ray diffraction (XRD) analysis (Fig. $3)^{24}$. In addition, there was no significant change in the XRD peak intensity before and after recycling, and no diffraction peak of graphitic carbon was found, indicating that there was no carbon deposit on the surface of the catalyst or the carbon deposit value was very low ${ }^{25}$. Therefore, the Fe-Mo/HZSM- 5 catalyst has high resistance to carbon deposition and stability. This also showed that the regeneration effect of the circulating regenerating fluidized bed was superior, effectively achieving catalyst regeneration and utilization.

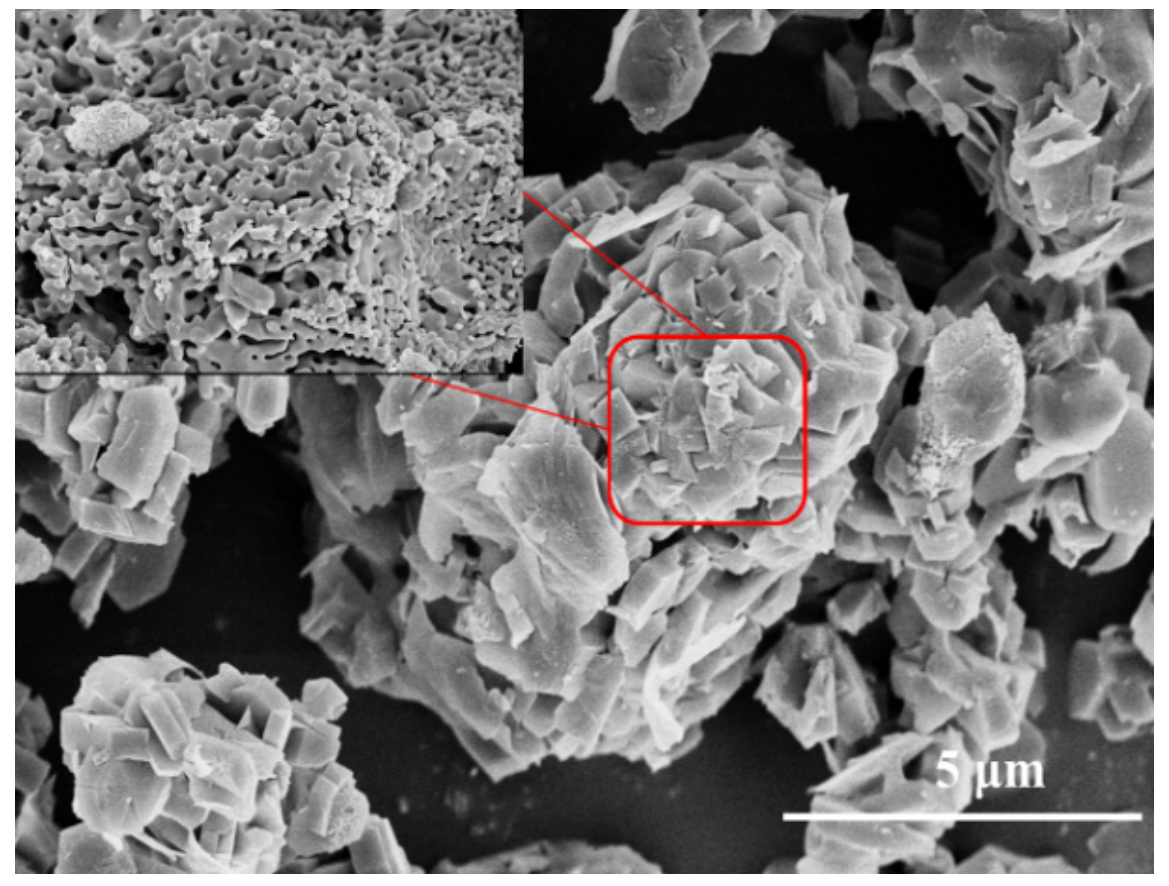


Fig.3. SEM image and XRD pattern of the catalyst after stability inspection .

\subsection{In-situ infrared exploration of reaction mechanism}

In the process of methanol oxidative polycondensation, there will be hydroxyl groups, carbonyl groups, and large lattice oxygen, which will generate formaldehyde, dimethyl ether, methyl formate and other byproducts.. In this study, the oxidative polycondensation of $\mathrm{O}_{2}+\mathrm{CH}_{3} \mathrm{OH}$ on Fe-Mo/ZSM-5 was analyzed using DRIFTS. Fig.4 shows the DRIFTS spectra of methanol adsorbed on Fe-Mo/ZSM-5 catalyst for different durations. The peak at about $3400-3600 \mathrm{~cm}^{-1}$ corresponded to the tensile vibration band of -OH and the peak at $2890 \mathrm{~cm}^{-1}$ corresponded to the antisymmetric and symmetric tensile vibration bands of the $\mathrm{C}-\mathrm{H}$ bond on methanol ${ }^{26}$. The peak at $2750 \mathrm{~cm}^{-1}$ corresponded to the stretching vibration of HCOO- ${ }^{27}$. The tensile vibration band at 1650-1725 $\mathrm{cm}^{-1}$ belongs to the carbonyl group, the tensile vibration band at about 1430 $\mathrm{cm}^{-1}$ belongs to -COO-, and the vibration band at $1100 \pm 50 \mathrm{~cm}^{-1}$ belongs to the ether bond R-O-R. The peak at $2120 \mathrm{~cm}^{-1}$ corresponded to the stretching vibration of $-\mathrm{OH}$ on the formate group ${ }^{28}$. At the same time, the deformation vibration of methyl ether in methylal can be observed at $900-1000 \mathrm{~cm}^{-1}$, which indicates that methanol is adsorbed on the surface of the catalyst to generate methoxy groups, and then desorbed to obtain $\mathrm{CH}_{3} \mathrm{O}$ for further polycondensation reaction ${ }^{29}$. Fig. 3 shows that, at a reaction time of 0.5 min, the characteristic peak intensities corresponding to the hydroxyl, carbonyl, and formic groups were all high, and the peak intensities corresponding to the ether bonds and methoxy groups were very weak. The large and broad peaks at 3500-2750 cm-1 in the first 3 minutes were mainly due to the formation of FA during the initial oxidation of methanol and the formation of a large number of water molecules ${ }^{30}$. As the reaction time increased, the vibration peak intensity of the carbonyl and formic acid groups gradually weakened, the peak intensity of -COO- increased slightly, and the methyl ether peak of DMM intensified ${ }^{5}$. These changes showed that methanol was first oxidized to form FA and a small amount of dimethyl ether (DME) on the Fe-Mo/ZSM-5 catalyst and then FA was further oxidized to form formic acid ${ }^{31}$. Then, FA and methanol underwent polycondensation to form DMM, and formic acid and methanol underwent polycondensation to form MF. After 7 minutes, there was almost no change in the peak intensities, which indicated that the reaction became stable. Therefore, DRIFTS analysis of methanol adsorption on the Fe-Mo/ZSM-5 catalyst for different reaction durations confirmed the previous theoretical speculation of all the chemical reactions and products that could occur in the process of preparing DMM from methanol by the one-step method ${ }^{32}$.

Fig.4. In situ DRIFTS spectra of the adsorption-oxidation- polycondensation of $\mathrm{CH}_{3} \mathrm{OH}$ on Fe-Mo/HZSM-5 catalysts, as a function of time on reaction. (a) $0.5 \mathrm{~min}$, (b) $2 \mathrm{~min}$, (c) $3 \mathrm{~min}$, (d) $5 \mathrm{~min}$, (e) $7 \mathrm{~min}$, (f) 10 min.

In-situ infrared spectroscopy was used to investigate the reaction of methanol on the Fe-Mo/ZSM-5 catalyst surface for different reaction times. This revealed that it took 7 minutes for the reaction to stabilize from contact. Therefore, under the same conditions, in-situ infrared spectroscopy was used to investigate the effect of changes in the Mo-Fe ratio and the $\mathrm{Si}-\mathrm{Al}$ ratio of the carrier on the reaction process ${ }^{33}$, with the results shown in Fig.5 (A) and (B), respectively. Table S3 shows the results of our previous findings on the catalytic activity of different Mo-Fe and Si-Al ratios ${ }^{34}$. Fig.5 (A) shows that as the Mo-Fe ratio increased, the peak intensity of the carbonyl, ether, and methoxy groups firstly weakened and then increased ${ }^{35}$. When $\mathrm{Mo}: \mathrm{Fe}=2$, the DMM methyl ether peak reached maximum intensity, which was consistent with the results in Table S3. Our team's previous research ${ }^{19}$ (adapted from ref. 8) found that Mo:Fe $=2$ was the optimal ratio and revealed that underpinning the Mo-Fe catalytic effect was the mutual promotion of the formation of the $\mathrm{Fe}_{2}\left(\mathrm{MoO}_{4}\right)_{3}$ octahedral crystal structure and molybdenum oxide tetrahedron formation. With an increase in the ratio of Mo to $\mathrm{Fe}$, the mutual promotion was greater, resulting in the further oxidation of part of the formaldehyde obtained by methanol oxidative dehydrogenation to obtain formic acid and MF as by-products ${ }^{36}$. Fig.5 (B) shows that the Fe-Mo/ZSM-5 catalyst with $\mathrm{Si}: \mathrm{Al}=80$ had the smallest peak intensities corresponding to hydroxyl, carbonyl, ether, and methoxy groups, and the highest intensity of the DMM methyl ether peak. Additionally, the methyl ether peak intensity of the Fe-Mo/ZSM-5 catalyst with $\mathrm{Si}: \mathrm{Al}=40$ was greater than that of the $\mathrm{Fe}-\mathrm{Mo} / \mathrm{ZSM}-5$ catalyst with $\mathrm{Si}: \mathrm{Al}=60 . \mathrm{In}$ previous studies ${ }^{37}$ (adapted from ref. 9), our team revealed that the tetrahedral coordination of $\mathrm{Al}$ provided Bronsted acid 
(B acid) sites and Lewis acid (L acid) sites on the Si-Al framework. Differences in the catalyst Si:Al ratio directly affected the distribution of $\mathrm{B}$ acid and $\mathrm{L}$ acid sites ${ }^{38}$.

Fig.5. In situ DRIFTS spectra of the adsorption-oxidation- polycondensation of $\mathrm{CH}_{3} \mathrm{OH}$ on different catalysts.(A) Fe-Mo/HZSM-5 catalysts with different Mo-Fe ratios (a) Mo-Fe ratio=1, (b) Mo-Fe ratio=2, (c) Mo-Fe ratio=3; (B) Fe-Mo/HZSM-5 catalysts with different $\mathrm{Si}: \mathrm{Al}$ ratio (d) $\mathrm{Si}: \mathrm{Al}$ ratio=40, (e) $\mathrm{Si}: \mathrm{Al}$ ratio $=60$, (f) $\mathrm{Si}: \mathrm{Al}$ ratio $=80$.

Fig.5 (C) shows the in-situ infrared spectroscopy results of Fe-Mo/ZSM-5 with different Si:Al ratios under the same conditions. In HZSM-5, the weak peak at $3745 \mathrm{~cm}^{-1}$ and the strong peak at $3610 \mathrm{~cm}^{-1}$ were attributed to the terminal silanol group ( $\mathrm{Si}-\mathrm{OH})$ and the acidic bridged hydroxyl group (Si-OH-Al), respectively ${ }^{39}$. The $\mathrm{Si}-\mathrm{OH}-\mathrm{Al}$ group is considered to be a $\mathrm{B}$ acid center, and the $\mathrm{B}$ acidity strength affects its structure. Fig.4(C) shows that the Si-OH-Al peak intensity gradually increased with increasing Si:Al, which proved that the $\mathrm{B}$ acidity of the catalyst gradually increased ${ }^{40}$. An important control step in the DMM production from methanol is the methanol acetalization stage, in which the B acid site of the catalyst plays a vital role. If the catalyst has no B acid sites, it is difficult for methanol to undergo acetalization to form DMM. Therefore, the in-situ infrared spectroscopy results in the present study further confirmed this previous theory. In-situ infrared spectroscopy also showed that the abundant oxygen vacancies on the Fe-Mo/ZSM-5 surface promoted the adsorption and oxidation of methanol to FA. These species could undergo further polycondensation at the acidic site of ZSM-5 to obtain DMM, which led to a positive shift in the reaction equilibrium. This synergistic effect of oxidation centers and acid centers may be the reason for the excellent catalytic performance obtained.

Based on these results, we summarized and proposed the reaction mechanism of methanol forming DMM under the action of Fe-Mo/ZSM-5 catalyst, as shown in Fig.6. Methanol and $\mathrm{O}_{2}$ were chemically adsorbed on the catalyst surface for the first time, with surface hydroxyl and oxygen vacancies, respectively. The presence of surface oxygen vacancies promoted the adsorption of $\mathrm{O}_{2}$ and further converted it into active oxygen species $\left(\mathrm{O}_{2}+\mathrm{Fe}^{3+}-\mathrm{Mo}^{6+}-\mathrm{O}^{2-}, \mathrm{O}^{-}\right)$, which react with the adsorbed methanol to form $\mathrm{FA}^{41}$. The $\mathrm{FA}$ was further oxidized at this oxidation vacancy to form formate, which directly decomposed into $\mathrm{CO}$ and $\mathrm{H}_{2} \mathrm{O}$. CO may exist as an intermediate and react quickly with $\mathrm{O}_{2}$ to form $\mathrm{CO}_{2}$, and therefore be undetected by in-situ infrared spectroscopy. Methanol and FA were chemically adsorbed on the catalyst surface for the second time with surface hydroxyl and carbonyl groups respectively ${ }^{42}$. The presence of L acid sites on the $\mathrm{Si}-\mathrm{Al}$ framework of the catalyst and $\mathrm{B}$ acid sites provided by the tetrahedral coordination of $\mathrm{Al}$ promoted the polycondensation of methanol and FA to form DMM, and at the same time generated a molecule of $\mathrm{H}_{2} \mathrm{O} . \mathrm{H}_{2} \mathrm{O}$ reacts with active oxygen to generate $-\mathrm{OH}\left(\mathrm{O}^{2-}+\mathrm{H}_{2} \mathrm{O}-2-\mathrm{OH}\right)$, and with formate to generate $\mathrm{CO}_{2}$ and $\mathrm{H}_{2} \mathrm{O}^{43}$. After the chemical adsorption of formic acid and methanol, MF was generated by the catalysis of $\mathrm{L}$ acid sites on the $\mathrm{Si}-\mathrm{Al}$ framework. Methanol generated DME by the catalysis of $\mathrm{B}$ acid sites provided by the tetrahedral coordination of Al. Since FA was the main intermediate in the formation of the target product DMM, the conversion of methanol to FA was likely to be the rate-determining step in the entire process. With the continuous supply of oxygen, the consumption of $\mathrm{O}^{2-}$ and $\mathrm{O}^{-}$would promote the coordination of two terminal oxygens and the Mo double bond in the $\mathrm{Fe}_{2}\left(\mathrm{MoO}_{4}\right)_{3}$ octahedron through the appearance of $\mathrm{Mo}^{5+}$ on the catalyst surface. This would coordinate the supply, resulting in methanol hydroxyl hydrogen activation to produce methoxy species. As these are intermediates formed by FA, the next step of the reaction could proceed quickly. Therefore, combined with our previous research findings, it could be concluded that the Fe-Mo/HZSM-5 catalyst has both acidic active centers and oxidation active centers. The former are due to the synergistic effect of the $\mathrm{L}$ acid on the Si-Al framework and the B acid provided by the tetrahedral coordination of $\mathrm{Al}$, promoting acidic active centers. The latter are due to the surface $\mathrm{Fe}_{2}\left(\mathrm{MoO}_{4}\right)_{3}$ octahedral crystal structure and the molybdenum oxide tetrahedron forming shared, mutually promoting oxidation active centers. To use Fe-Mo/ZSM-5 dual functional catalyst to selectively obtain more target products, it is necessary to achieve synergistic selective catalysis by these two activation centers. 


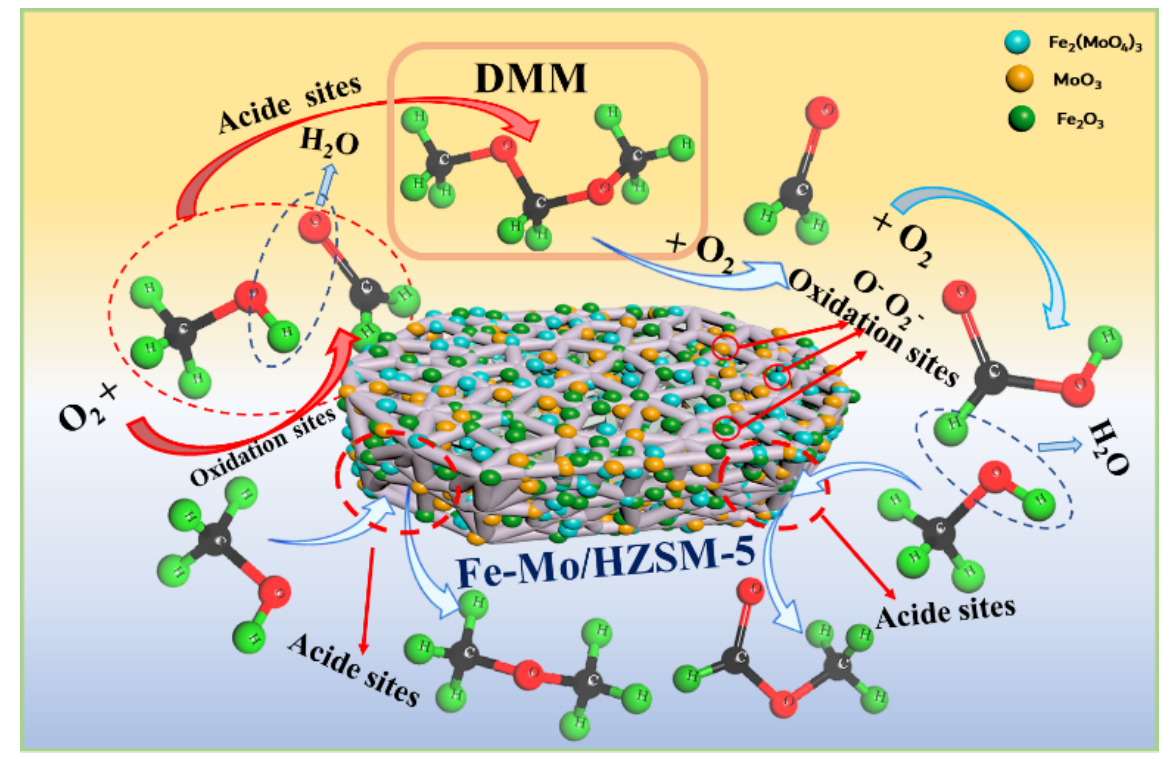

Fig.6. Schematic of the reaction mechanism of methanol over the surface of Fe-Mo/ZSM-5 catalysts.

\section{Conclusion}

In conclusion, the pilot experiment of the circulating fluidized bed scaled-up reactor was successful, with the Fe-Mo/ZSM-5 catalyst enabling the production of the valuable product DMM with a sustainable high yield. The influence of the change of reaction conditions on the product distribution was explored. After a long period of operation in the circulating fluidized bed, the Fe-Mo/ZSM-5 catalyst was shown to have high stability and carbon deposition resistance, and the regeneration effect of the circulating regeneration fluidized bed was better. In situ infrared spectroscopy was used to explore the effect of the reaction time on the reaction of methanol and the product distribution. It was found that methanol was first oxidized to form FA and a small amount of DME on the Fe-Mo/ZSM-5 catalyst, following which FA further oxidized to form formic acid. Then, FA and methanol underwent polycondensation to form DMM, and formic acid and methanol underwent polycondensation to form MF. In situ infrared spectroscopy was also used to explore the influence of changes in the ratio of $\mathrm{Mo}$ to $\mathrm{Fe}$ and the ratio of $\mathrm{Si}$ to $\mathrm{Al}$ in the carrier on the reaction and product distribution. It was found that the synergistic effect of oxidation centers and acid centers was the basic reason for the excellent catalytic performance of the Fe-Mo/ZSM-5 catalyst. Finally, through in-situ online exploration, the reaction mechanism of the one-step process of preparing DMM from methanol was proposed. These studies have laid the foundation for the in-depth development, promotion and application of new technology.

\section{Acknowledgements}

This study was conducted with National Natural Science Foundation of China (No. 21878335, 21576293 and 21576294), Major scientific and technological innovation projects in Shandong Province of China (No. 2018CXGC0301), the Key Research and Development Program of Shaanxi(No. 2020ZDLSF06-10), Natural Science Basic Research Program of Shaanxi(No. 2021JQ-668) and the Shandong Natural Science Foundation (ZR2017QEE006).

\section{Reference}

1. Fu Y, Shen J. Production of hydrogen by catalytic reforming of dimethoxymethane over bifunctional catalysts. Journal of Catalysis. 2007;248(1):101-110. 
2. Kaichev VV, Popova GY, Chesalov YA, et al. Selective oxidation of methanol to form dimethoxymethane and methyl formate over a monolayer $\mathrm{V}_{2} \mathrm{O}_{5} / \mathrm{TiO}_{2}$ catalyst. Journal of Catalysis. 2014;311:59-70.

3. Lu X, Qin Z, Dong M, et al. Selective oxidation of methanol to dimethoxymethane over acid-modified $\mathrm{V}_{2} \mathrm{O}_{5} / \mathrm{TiO}_{2}$ catalysts. Fuel. 2011;90(4):1335-1339.

4. Royer S, Secordel X, Brandhorst M, et al. Amorphous oxide as a novel efficient catalyst for direct selective oxidation of methanol to dimethoxymethane. Chemical Communication Feb 21 2008(7):865-867.

5. Whiting GT, Kondrat SA, Hammond C, et al. Methyl Formate Formation from Methanol Oxidation Using Supported Gold-Palladium Nanoparticles. ACS Catalysis. 2014;5(2):637-644.

6. Awad OI, Ma X, Kamil M, Ali OM, Ma Y, Shuai S. Overview of polyoxymethylene dimethyl ether additive as an eco-friendly fuel for an internal combustion engine: Current application and environmental impacts. Sci Total Environ. May 1 2020;715:136849.

7. Li H, Song H, Chen L, Xia C. Designed $\mathrm{SO}_{4}{ }^{2-} / \mathrm{Fe}_{2} \mathrm{O}_{3}-\mathrm{SiO}_{2}$ solid acids for polyoxymethylene dimethyl ethers synthesis: The acid sites control and reaction pathways. Applied Catalysis B: Environmental. 2015;165:466476.

8. Xue Z, Shang H, Zhang Z, Xiong C, Lu C, An G. Efficient Synthesis of Polyoxymethylene Dimethyl Ethers on Al-SBA-15 Catalysts with Different Si/Al Ratios and Pore Sizes. Energy E3 Fuels.2016;31(1):279-286.

9. Zhang L, Chen L, Li Y, et al. Complete oxidation of formaldehyde at room temperature over an Al-rich Beta zeolite supported platinum catalyst. Applied Catalysis B: Environmental.2017;219:200-208.

10. Wu Y, Li Z, Xia C. Silica-Gel-Supported Dual Acidic Ionic Liquids as Efficient Catalysts for the Synthesis of Polyoxymethylene Dimethyl Ethers. Industrial \&3 Engineering Chemistry Research.2016;55(7):1859-1865.

11. Chen S, Meng Y, Zhao Y, Ma X, Gong J. Selective Oxidation of Methanol to Dimethoxymethane over Mesoporous Al-P-V-O Catalysts.AIChE Journal. 2013;59(7):2587-2593.

12. Zhan E, Li Y, Liu J, Huang $\mathrm{X}$, Shen W. A VOx/meso- $\mathrm{TiO}_{2}$ catalyst for methanol oxidation to dimethoxymethane. Catalysis Communications.2009;10(15):2051-2055.

13. Yuan Y, Shido T, Iwasawa Y. The new catalytic property of supported rhenium oxides for selective oxidation of methanol to methylal. Chemical Communications. 2000(15):1421-1422.

14. Wang T, Meng Y, Zeng L, Gong J. Selective oxidation of methanol to dimethoxymethane over $\mathrm{V}_{2} \mathrm{O}_{5} / \mathrm{TiO}_{2}-\mathrm{Al}_{2} \mathrm{O}_{3}$ catalysts. Science Bulletin. 2015;60(11):1009-1018.

15. Nikonova OA, Capron M, Fang G, et al. Novel approach to rhenium oxide catalysts for selective oxidation of methanol to DMM. Journal of Catalysis. 2011;279(2):310-318.

16. Zhang Q, Tan Y, Yang C, Han Y. $\mathrm{MnCl}_{2}$ modified $\mathrm{H}_{4} \mathrm{SiW}_{12} \mathrm{O}_{40} / \mathrm{SiO}_{2}$ catalysts for catalytic oxidation of dimethy ether to dimethoxymethane.Journal of Molecular Catalysis A: Chemical.2007;263(1-2):149-155.

17. Chen S, Wang S, Ma X, Gong J. Selective oxidation of methanol to dimethoxymethane over bifunctional VO(x)/TS-1 catalysts. Chem Commun (Camb). Sep 7 2011;47(33):9345-9347.

18. Han S, Chen Y, Lyu S, Chen Z, Wang S, Fu F. Effects of processing conditions on the properties of paraffin/melamine-urea-formaldehyde microcapsules prepared by in situ polymerization. Colloids and Surfaces A: Physicochemical and Engineering Aspects. 2020;585:124046.

19. Yuan $\mathrm{M}$, Che $\mathrm{Y}$, Tang $\mathrm{R}$, et al. One-step synthesis of methylal via methanol oxidation by Mo:Fe(x)/HZSM-5 bifunctional catalyst. Fuel. 2020;261:116416.

20. Liu H, Iglesia E. Selective One-Step Synthesis of Dimethoxymethane via Methanol or Dimethyl Ether Oxidation on $\mathrm{H}_{3+\mathrm{n}} \mathrm{VnMo}_{12-\mathrm{n}} \mathrm{PO}_{40}$ Keggin Structures. Journal of Physical Chemistry B.2003;107:1084010847. 
21. Jin G, Weng W, Lin Z, et al. $\mathrm{Fe}_{2}\left(\mathrm{MoO}_{4}\right)_{3} / \mathrm{MoO}_{3}$ nano-structured catalysts for the oxidation of methanol to formaldehyde. Journal of Catalysis. 2012;296:55-64.

22. Zhao $\mathrm{Y}$, Qin $\mathrm{Z}$, Wang $\mathrm{G}$, et al. Catalytic performance of $\mathrm{V}_{2} \mathrm{O}_{5} / \mathrm{ZrO}_{2}-\mathrm{Al}_{2} \mathrm{O}_{3}$ for methanol oxidation. Fuel. 2013;104:22-27.

23. Im J, Park S, Lee Y. The metal-carbon-fluorine system for improving hydrogen storage by using metal and fluorine with different levels of electronegativity. International Journal of Hydrogen Energy. 2009;34(3):1423-1428.

24. Xia H, Liu Z, Xu Y, Zuo J, Qin Z. Highly efficient V-Mo-Fe-O catalysts for selective oxidation of toluene to benzaldehyde.Catalysis Communications. 2016;86:72-76.

25. Liu Q, Gao J, Gu F, et al. One-pot synthesis of ordered mesoporous $\mathrm{Ni}-\mathrm{V}-\mathrm{Al}$ catalysts for $\mathrm{CO}$ methanation. Journal of Catalysis. 2015;326:127-138.

26. Salisu J, Gao N, Quan C. Techno-Economic Assessment of Co-Gasification of Rice Husk and Plastic Waste as Off-Grid Power Source for Small Scale Rice Milling in Nigeria-an Aspen Plus Model.Journal of Analytical and Applied Pyrolysis. 2021:105157.

27. Li K, Ji J, Huang $\mathrm{H}$, He M. Efficient activation of $\mathrm{Pd} / \mathrm{CeO}_{2}$ catalyst by non-thermal plasma for complete oxidation of indoor formaldehyde at room temperature. Chemosphere. May 2020;246:125762.

28. Li D, Xing B, Wang B, Li R. Activity and selectivity of methanol-to-olefin conversion over Zr-modified H-SAPO-34/H-ZSM-5 zeolites - A theoretical study. Fuel Processing Technology.2020;199:106302.

29. Barbosa SL, Lima PC, dos Santos WTP, Klein SI, Clososki GC, Caires FJ. Oxygenated biofuels: Synthesis of fatty acid solketal esters with a mixture of sulfonated silica and (Bu4N)(BF4) catalyst. Catalysis Communications. 2019;120:76-79.

30. DePuccio DP, Ruíz-Rodríguez L, Rodríguez-Castellón E, Botella P, López Nieto JM, Landry CC. Investigating the Influence of $\mathrm{Au}$ Nanoparticles on Porous $\mathrm{SiO}_{2}-\mathrm{WO}_{3}$ and $\mathrm{WO}_{3}$ Methanol Transformation Catalysts. The Journal of Physical Chemistry C. 2016;120(49):27954-27963.

31. He M, Ji J, Liu B, Huang H. Reduced $\mathrm{TiO}_{2}$ with tunable oxygen vacancies for catalytic oxidation of formaldehyde at room temperature. Applied Surface Science. 2019;473:934-942.

32. Li X, Cao J, Nawaz MA, Liu D. Synergy of Lewis and Brønsted acid sites for polyoxymethylene dimethyl ether synthesis from methanol and formaldehyde solution over $\mathrm{Zr}^{4+}$ modified sulfonated resin. Fuel. 2021;289:119867.

33. Losch P, Pinar AB, Willinger MG, et al. H-ZSM-5 zeolite model crystals: Structure-diffusion-activity relationship in methanol-to-olefins catalysis. Journal of Catalysis.2017;345:11-23.

34. Qi J, Hu Y, Jiang S, Ma W, Yang Z, Wang Y. Lewis acids promote the catalytic selectivity to polyoxymethylene dimethyl ethers PODE $_{3,4}$. Fuel. 2019;245:521-527.

35. Wang F, Zhu G, Li Z, Zhao F, Xia C, Chen J. Mechanistic study for the formation of polyoxymethylene dimethyl ethers promoted by sulfonic acid-functionalized ionic liquids. Journal of Molecular Catalysis A: Chemical. 2015;408:228-236.

36. Zhang J, Fang D, Liu D. Evaluation of Zr-Alumina in Production of Polyoxymethylene Dimethyl Ethers from Methanol and Formaldehyde: Performance Tests and Kinetic Investigations. Industrial $\& 5$ Engineering Chemistry Research.2014;53(35):13589-13597.

37. Yuan M, Tang R, Sun X, Zhang Z, Tian Y, Qiao Y. Effects of the support on bifunctional one-step synthesis of methylal via methanol oxidation catalysed by Fe-Mo-based bifunctional catalysts.Sustain. Energ. Fuels. 2021;5(1):246-260. 
38. Wang Q, Feng Z, He H, et al. Nonblinking carbon dots for imaging and tracking receptors on a live cell membrane. Chem Commun (Camb). Jun 7 2021;57(45):5554-5557.

39. Rostamizadeh M, Yaripour F, Hazrati H. Ni-doped high silica HZSM-5 zeolite ( $\mathrm{Si} / \mathrm{Al}=200$ ) nanocatalyst for the selective production of olefins from methanol. Journal of Analytical and Applied Pyrolysis. 2018;132:110.

40. Joyner R, Stockenhuber M. Preparation, Characterization, and Performance of Fe-ZSM-5 Catalysts. Journal of Physical Chemistry B. 1999;103:5963-5976.

41. Routray K, Zhou W, Kiely CJ, Grunert W, Wachs IE. Origin of the synergistic interaction between $\mathrm{MoO}_{3}$ and iron molybdate for the selective oxidation of methanol to formaldehyde.Journal of Catalysis. 2010;275(1):84-98.

42. Shinde VM, Madras G. CO methanation toward the production of synthetic natural gas over highly active $\mathrm{Ni} / \mathrm{TiO}_{2}$ catalyst. AIChE Journal.2014;60(3):1027-1035.

43. Yuan M, Shao Y, Tang R, et al. Study on the application of sulfonation catalysis in a new formaldehyde recovery process. Colloids and Surfaces A: Physicochemical and Engineering Aspects.2021;630:127593. 